\title{
Anticipatory eye movements when approaching a curve on a rural road depend on working memory load
}

\section{Lehtonen, Esko}

2012

Lehtonen , E , Lappi , O \& Summala , H 2012 , ' Anticipatory eye movements when approaching a curve on a rural road depend on working memory load ' , Transportation

Research. Part F: Traffic Psychology and Behaviour, vol. 15 , no. 3 , pp. 369-377 . https://doi.org/10.1016/j.trf.2011

http://hdl.handle.net/10138/32905

https://doi.org/10.1016/j.trf.2011.08.007

acceptedVersion

Downloaded from Helda, University of Helsinki institutional repository.

This is an electronic reprint of the original article.

This reprint may differ from the original in pagination and typographic detail.

Please cite the original version. 


\section{Anticipatory eye movements when approaching a curve on a rural road depend on working memory load}

Lehtonen E. ${ }^{a, b}$, Lappi O. ${ }^{a, b}$, \& Summala H. ${ }^{a}$

${ }^{a}$ Traffic Research Unit, Institute of Behavioural Sciences, University of Helsinki, Finland.

${ }^{b}$ Cognitive Science, Institute of Behavioural Sciences, University of Helsinki, Finland.

This is authors' revised personal version of an article published as:

Lehtonen, E., Lappi, O., Summala, H. (2011). Anticipatory eye movements when approaching a curve on a rural road depend on working memory load, Transportation Research Part $F$. doi: 10.1016/j.trf.2011.08.007

The article may not exactly replicate the version published in the journal.

a Postal address

Traffic Research Unit, Box 9 Institute of Behavioural Sciences FIN-00014 University of Helsinki Finland

${ }^{\mathrm{b}}$ Postal address Cognitive Science, Box 9 Institute of Behavioural Sciences FIN-00014 University of Helsinki Finland
Corresponding author:

\author{
Esko Lehtonen \\ esko.lehtonen@helsinki.fi \\ +358-9-191 29421 \\ Traffic Research Unit, Box 9 \\ Institute of Behavioral Sciences \\ FIN-00014 University of Helsinki \\ Finland
}

Email addresses:

Otto Lappi,

otto.lappi@helsinki.fi

Heikki Summala,

heikki.summala@helsinki.fi 


\section{ABSTRACT}

Where do drivers look when approaching curves on a winding road? Existing models on visual processes in curve driving have focused on path-controlling behaviour. Another aspect in curve driving is the visual anticipation of potential oncoming vehicles, obstacles and road alignment. We define the occlusion point of a curve as the nearest point where the view of the road is blocked by some obstacle (e.g. vegetation). Monitoring the occlusion point is relevant for safe driving because potential oncoming vehicles or obstacles on the road will come into view on the occlusion point.

In the current on-road study, ten participants drove an instrumented car at their own pace on a low standard rural road while their eye-movements were recorded. We investigated anticipatory glances towards the occlusion point while approaching open sight curves and how anticipatory glances are affected by a cognitive secondary task without explicit visuospatial or motor components.

The results demonstrate that drivers indeed look at the occlusion point while approaching open curves on rural roads, and that working memory load leads to a significant decrease in visual anticipation. Previously, it has been shown that cognitive secondary tasks lead to reduction of looking at the speedometer and mirrors and of safety critical visual scanning at street crossings. We show that the effect is also present in the anticipation of road curvature and hazards on rural roads.

Keywords: Car driving, Rural Roads, Anticipation, Cognitive Load, Occlusion Point, Tangent Point 


\section{Introduction}

Driving is one of the few domains in our everyday life where misjudgements can have devastating, potentially fatal, consequences. Anticipation - keeping an eye out for potential hazards at distance, such as oncoming cars, and obstacles on the road - is an important part of safe driving. In order to maintain sufficient safety margins to potential hazards, drivers need to attend to spots which are the most likely sources of hazards. Also, in an unfamiliar road, drivers need to keep an eye on road curvature and elevation changes and irregularities of the road surface.

Previous research on visual processes in curve driving has focused on perceiving curvature (Shinar, McDowell \& Rockwell, 1977; Fildes \& Triggs, 1985, Charlton, 2007) and path selection and line keeping (e.g. Donges, 1978; Land \& Lee, 1994; Land \& Horwood, 1995; Salvucci \& Gray, 2004; Wann \& Swapp, 2000). The following relevant areas of interest in the road view have been identified in the literature (Fig. 1):

1.The tangent point (TP) is the apparent reversal point of visual curvature on the inside of a curve, equivalently, the point where gaze direction is tangential to the road edge (Land \& Lee, 1994).

2. The near point and the far point (NP, FP) are points on the road, immediately in front of the car, and further up the road, respectively. Land and Horwood (1995) and Salvucci and Gray (2004) have shown how a driver might use these points as reference points for steering.

3.In straight sections of a road the focus of optical expansion (FOE) is a point lying directly ahead where the apparent flow patterns generated by elements in the visual scene symmetrically radiate from (Gibson, 1958).

The current curve driving models do not account for anticipation of oncoming cars or obstacles. Also, on-road studies of driving through curves have typically concerned traffic conditions where there is little need for the driver to anticipate the road ahead for oncoming traffic, such as one-way roads (Land \& Lee, 1994) and motorway ramps (Kandil, Rotter \& Lappe, 2009). While Kandil, Rotter \& Lappe (2010) mentioned "long-lasting gazes to the end of the visible road", they did not attempt a quantitative characterization of this behaviour. 
As far as we know, Underwood, Chapman, Crundall, Cooper \& Wallén (1999) is the only field study that has explicitly addressed the anticipatory function in visual control of driving through a curve. They hypothesized that drivers look at the area near the tangent point not only to receive information of the curvature and to control steering (as suggested by Land and Lee, (1994)) but also to spot potential hazards. They found that drivers fixate to the tangent point area in open curves more than in closed ones. Closed curves force drivers to continuously divide attention between steering and hazard detection, while in open curves "drivers are able to check the road ahead for oncoming traffic or other hazards quite easily [and] can focus their visual attention on the task [of] steering". However, the authors did not present a detailed analysis of the fixations that fell outside the tangent point area in both curve types, and their analysis apparently contained driving through the curve, not the anticipatory behaviour that already occurs on straight sections preceding open curves.

The aim of the current study is to investigate visual anticipation when approaching a curve. For this purpose we explicitly define a fourth area of interest (Fig. 1):

4. The occlusion point (OP) of a curve is the nearest point where the view of the road is blocked by some obstacle (e.g. vegetation). The oncoming traffic will usually first emerge from the region of the occlusion point. The location of this point on the ground changes as a car travels along a road and can even jump suddenly if elevation changes or vegetation or other sight obstacles obstruct or reveal the road ahead. While the occlusion point is usually the furthermost visible point on the road, that is not the case if the obstacle blocks only a stretch of the road.

The occlusion point is defined within curves as well as within the straight segments preceding them. In closed curves the occlusion point falls very close to the tangent point but in open curves there will be a substantial angular distance between the tangent point and the occlusion point, allowing us to resolve unambiguously which one the driver is fixating on.

In the current context of approaching curves with open view on rural roads, we will assume that glances towards the occlusion point of the curve reflect exploration of road direction and search for potential hazards. Consequently, we will call the behaviour as visual anticipation. 


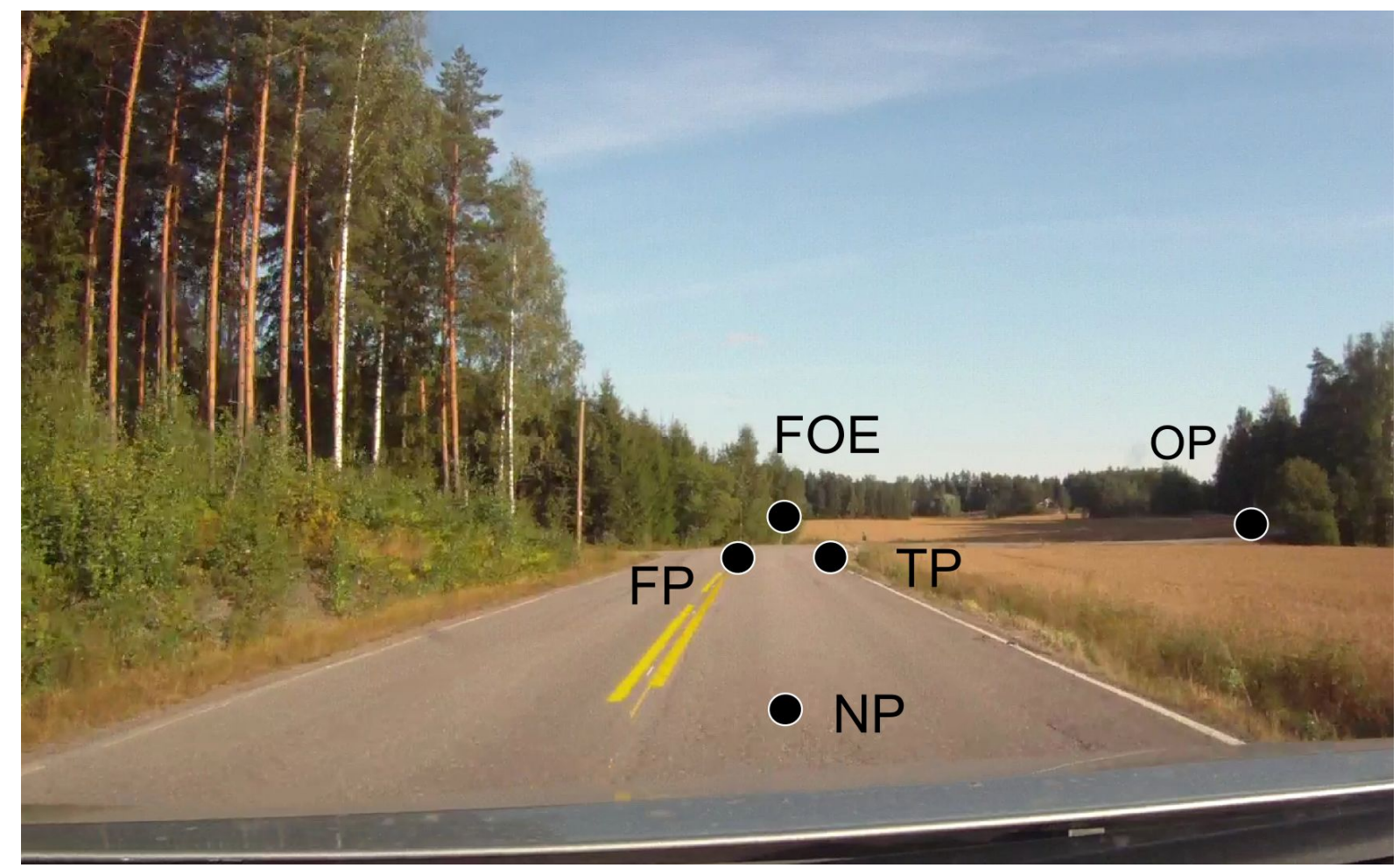

Fig 1. In-car view of an approach to the right hand curve used in the study. The driver is approaching the right hand curve on a clear 100 meter stretch of straight road. Some behaviourally relevant parts of the visual scene are illustrated. FOE: Focus of optical expansion (Gibson, 1958). TP: Tangent point (Land and Lee, 1994). NP, FP: Near point and far point, respectively (Salvucci \& Gray, 2004). OP: Occlusion point of the curve, which is here the point where the road becomes occluded by vegetation.

\subsection{Working memory load and visual anticipation}

Driving is an example of everyday multitasking. Some of the subtasks are not endogenous to the driving, like conversing with passengers or via mobile phone. Conversation has many similarities to typical cognitive secondary tasks used in traffic research, where participants are required to manipulate and maintain verbally administered stimuli in their working memory and also give responses verbally. It is well established that cognitive secondary tasks (which do not explicitly require drivers' visual attention) lead to concentration of gaze to road ahead and away from periphery (Reimer, 2009; Harbluk, Noy, Trbovich \& Eizenman, 2007; Victor, Harbluk \& Engström, 2005). This is reflected in reduction of variation in gaze direction (Victor et al. 2005; Recarte \& Nunes, 2000). In the current study, a demanding 
working memory task was used to simulate intensive discussion. A working memory task was used instead of natural discourse because the task allowed better control of the level of cognitive load.

Other visual functions requiring eccentric fixations, such as glances to speedometer and to interior mirrors (Cohen \& Studach, 1977; Recarte \& Nunes, 2000; Harbluk et al., 2007) and even safety critical visual search for traffic at street crossings (Gruzdaitis, Karola, Kotiranta, Lamble \& Summala, 2004) have been shown to reduce or even get left out under cognitive load. It is possible that glances towards the occlusion point - which may be located at eccentricities of more than 10 degrees - would also be affected by cognitive load.

The first aim of this study was to quantitatively show that visual anticipation occurs in normal driving on rural roads. Specifically, we wanted to see if the driver would divert her gaze away from the parts of the visual scene that have previously been shown to be important for lane keeping and line selection (i.e. the far point and the tangent point) in an anticipatory manner (i.e. towards the occlusion point). We expected that anticipation of traffic conditions and the road ahead should decrease or even drop out altogether with increasing cognitive load.

We assumed that anticipatory glances would occur for two reasons: First, in order to anticipate road curvature and elevation changes, and, secondly, to spot oncoming hazards. Road familiarity should reduce the need for anticipation because with experience (successive runs along the same road), the driver could form a mental representation of the upcoming road, and there would be less need for visual search, as the curve could be driven partially from memory. Still, visual anticipation would not drop out altogether as there would still remain the need to look out for oncoming traffic.

\section{Materials and methods}

\subsection{Participants}

Ten subjects participated in the experiment ( 6 male, 4 female, age $25-52$ years, $M 30, S D 8$ years). Participants were recruited through university mailing lists and personal contacts 
among students and their friends and family. Participants gave an informed consent to take part in the study.

Conditions for inclusion in the experiment were normal uncorrected vision and sufficient driving experience. All had held a valid driving license for at least 5 years and reported lifetime driving experience of more than $20000 \mathrm{~km}$. The reason for choosing relatively experienced subjects was that with experience drivers learn to keep the car in lane with peripheral vision, without the need to fixate the side of the road (near points) for keeping lateral position (Mourant \& Rockwell, 1972; Summala, Nieminen \& Punto, 1996). This was deemed to give us the best chance of observing anticipation, as the drivers would not spend time looking at the road surface near the car.

\subsection{Equipment}

The instrumented car was a Toyota Corolla compact sedan with a manual transmission (model year 2007). The car was equipped with a two-camera Smart Eye Pro 5.1 eye tracker (www.smarteye.se) operating at $60 \mathrm{~Hz}$, a forward looking VGA video camera and a GPSreceiver. Vehicle speed and use of vehicle controls was recorded from the CAN-bus. The passenger side was equipped with a brake pedal and extra mirrors.

\subsection{Test route}

The test route consisted of a $17.7 \mathrm{~km}$ section of low-standard rural road with $6.5 \mathrm{~m}$ of pavement width and painted center line and edge lines. The route was divided into two recording segments, $3.9 \mathrm{~km}$ and $2.0 \mathrm{~km}$ in length and driven in both directions, making a total of four recording segments per run and thus amounting to $5.9 \mathrm{~km}$ per run.

Two open curves (one left hand and one right hand turn, see Fig.2) were selected for detailed analysis. The two curves were located in the opposite ends of a straight segment of $100 \mathrm{~m}$. The straight segment of the road and the curves were adjacent to an open field. Consequently, the drivers needed to make eccentric fixations away from the road ahead in order to fixate the occlusion point. 


\subsection{Procedure}

A participant first filled a questionnaire regarding their driving background. The participant was then instructed to adjust the driver's seat of the vehicle as upright as she comfortably could in order to minimize longitudinal head movements which could distract the eye tracker. Stability of the head and driver comfort was checked by driving a short test run. After adjusting the driving position an eye-tracker profile was created and calibrated.

In addition to the participant who drove the car, there were two other persons in the car during the experiment. A member of university staff acted as driving instructor on front seat giving route directions and ensuring safety. A research assistant on the back seat (driver's side) gave the stimuli during the secondary task and recorded the answers.

The participant drove the car to the area located $34 \mathrm{~km}$ from the campus, giving them time to familiarize them with the car as well as practice the secondary task. A few kilometers before arriving at the test site, the instrument cluster was occluded in order to reduce downwards glances to the speedometer during the test runs which could interfere with the measurement. The driving instructor had access to the vehicle speed through a separate display, in case the driver would not have been able to maintain a safe level of speed. Participants did not express serious discomfort at having to drive without a speedometer, and generally considered that they were able to drive quite naturally.

In the experiment participants drove the prespecified route at their own pace, either normally ("free" condition) or while performing the cognitive secondary task ("load" condition). Each participant drove the route twice in free condition and once in load condition. The order of runs in free and load condition was counterbalanced between subjects.

The participants were instructed to drive as they normally would, but to observe traffic laws and safety, in particular not to cut into the lane of oncoming traffic in left-hand turns (even if this was what they would do in normal driving). If a driver failed to comply she was reminded of this by the driving instructor immediately after the segment. If, approaching the test route, there was a leading vehicle the driving instructor advised the driver to pull over 
and wait until the vehicle was no longer visible. Interaction within the car was avoided during the recording segments.

After each run, the driver was asked to pull over and to complete a self-report questionnaire based on the NASA-TLX (Lehtonen, Dahlström, Hiltunen \& Summala, 2010). The questionnaire assessed subjectively experienced valence, physical and mental load and concentration on vehicle controls.

\subsection{The secondary task SPASAT}

As the cognitive secondary task we used a self-paced variant of the PASAT task (Sampson, 1956; Gronwall, 1977), referred to below as SPASAT (Self Paced Serial Addition Task; Kauranen, Lamble, Laakso, \& Summala, 1997; Lamble, Kauranen, Laakso, \& Summala, 1999). The experiment instructor read out two numbers between 1 and 9. The driver's task was to mentally add the two latest numbers together and to report the result verbally. Immediately after the driver gave an answer, the experiment instructor gave a single new number. Thus, the task required the driver to keep the last number the experimenter had given in working memory during reporting the answer, and then encode the new number, add this to the number in working memory, and commit the new number to working memory while reporting the sum. If the driver was unable to provide an answer, she would say "pass", and the instructor would give two new numbers to add. Two numbers were always given in the beginning of each recording segment. Wrong answers were recorded, but the driver was not corrected. The time when a new number was given was manually recorded by the instructor using a keypad.

\subsection{Calculation of anticipation measure}

The angles of the occlusion points in the beginning of the straight segment were calculated from aerial photographs (Fig. 2). In the left hand curve, the occlusion point was at 25 degrees left. In the right hand curve, the heading was 12 degrees right. When approaching the curve, the occlusion point increases in eccentricity.

Based on comparison of eye movement visualization in the recorded videos and the eye movement graphs (for an example, see Fig. 3), horizontal eccentricity of gaze was deemed to be an appropriate measure to distinguish anticipatory glances from other eye-movement 
behaviour. (There was practically no eye movements captured by the eccentricity criterion which could be classified as not directed towards the occlusion point).

The gazes over a threshold of ten degrees towards the occlusion point were classified as visual anticipation. The subject's total anticipation for a run was then defined as the percentage of recorded observations which satisfied the eccentricity criterion. The anticipation measure was calculated from the beginning of the straight section up to the point where the driver was two seconds away from the point where they would typically turn in to the curve. We used two seconds distance because this was the estimate of the point where the drivers may start using the tangent point, according to Land and Lee (1994).

Missing data points in the recording (12\%) were included in the total percentage as nonanticipatory observations, so the anticipation measure is a conservative estimate of the percentage of time spent looking towards the occlusion point. (Exclusion of the missing data points and re-calculating the percentages did not affect the results substantially.) 


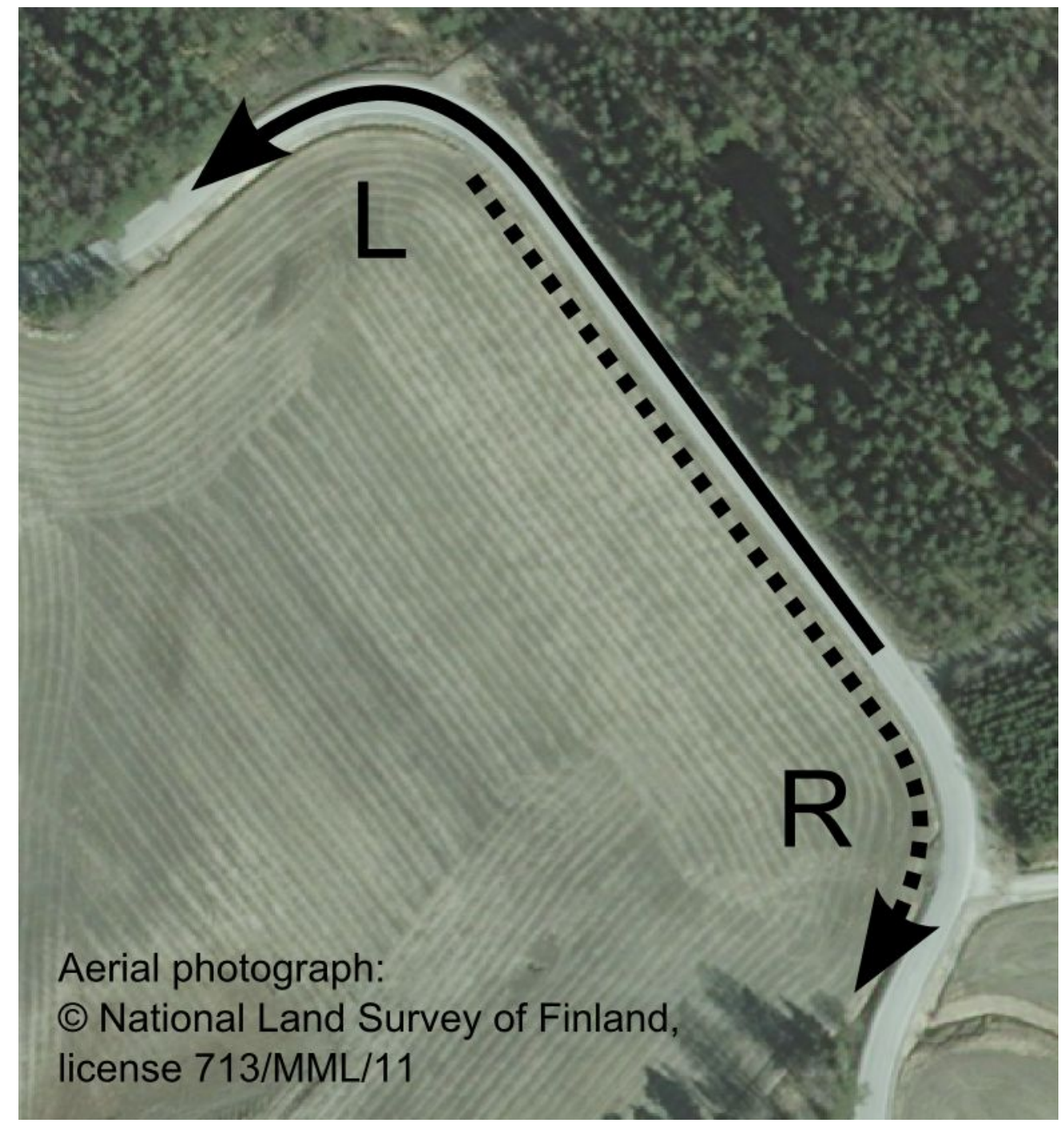

Fig 2. Aerial photograph with annotations: the left curve ( $L$, solid) and the right curve $(R$, dotted) used in the study.. Aerial photograph: (c) National Land Survey of Finland, license $713 / M M L / 1$.

\subsection{Data analysis}

If there was oncoming traffic in either the straight section or the curve (any vehicles or pedestrians visible in the forward-looking video camera in the time-window from which the data was analyzed), the data for that curve on that run was excluded from the analyses (three cases in the right-hand turn, and three cases in the left-hand turn). Finally, one free run was excluded because of momentary loss of eye tracking.. 
The effect of the secondary task on visual anticipation was tested by comparing the anticipation measure of the loaded run to the mean of the free runs. If one of the free runs was missing, the sole remaining run was used. One participant was missing altogether from task condition comparison because the loaded runs from the both curves were excluded. This resulted in nine participants for both curves whose eye tracking data could be used in pairwise comparison.

All statistical analyzes were done with SPSS 16.

\section{Results}

\subsection{Visual anticipation}

Fig. 3 shows an example of eye recoding data when a participant drives through the right hand curve three times consecutively, twice without and once with the secondary cognitive load task. It can be seen very clearly that the driver looks to the right towards the occlusion point at quite similar locations along the straight segment preceding the curve when not under cognitive load. This anticipatory behaviour drops out when the driver is performing a demanding working memory task. 


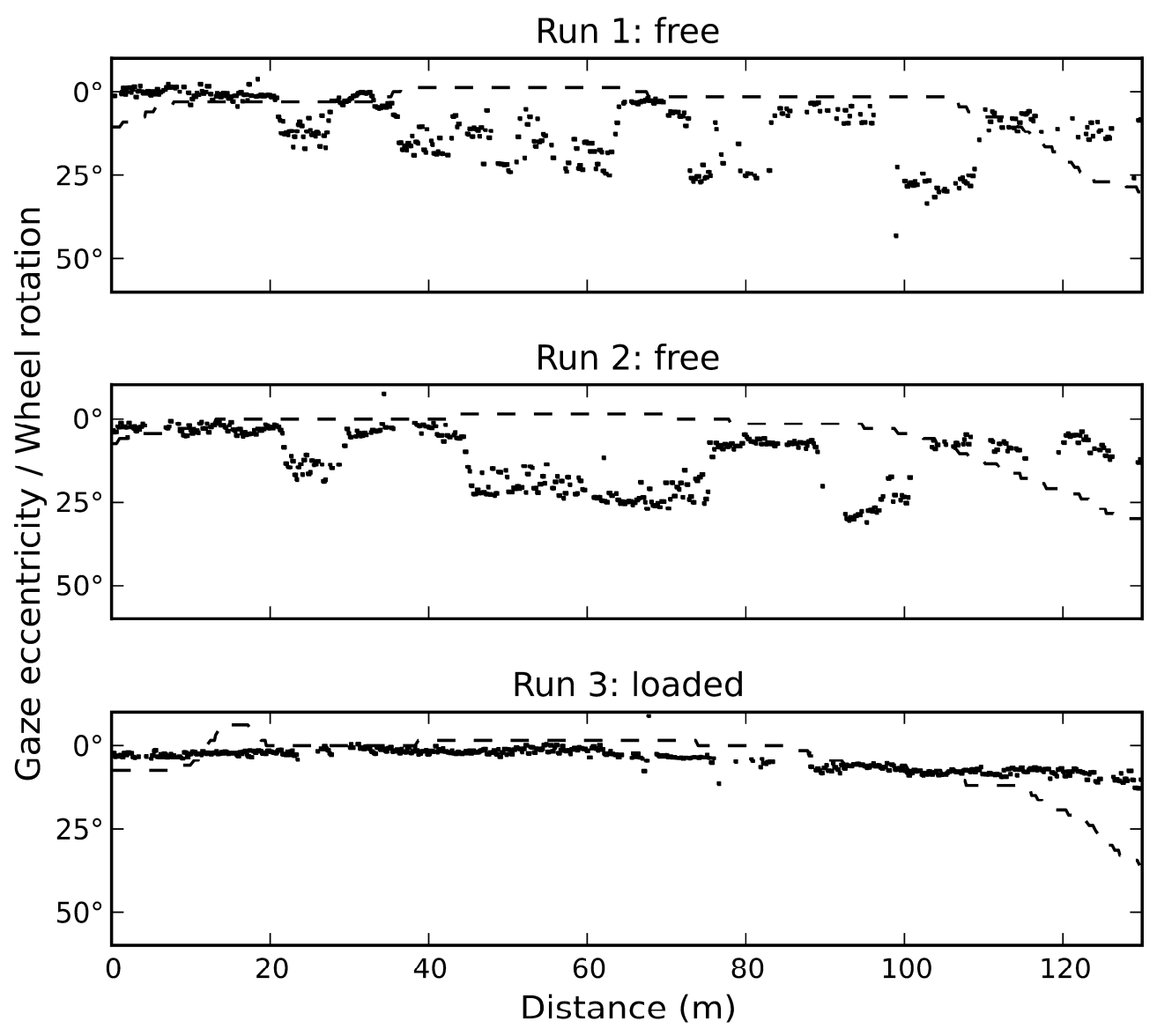

Fig. 3. Data from the same road section from one participant over the runs. Gaze heading measurements (dots) are plotted as relative to the car interior. Rotation of steering wheel (dashed line) is added to indicate the beginning of the curve. Positive y-values stand for left and negative $y$-values for right. Distance in meters on the $x$-axis is calculated from the beginning of the straight segment used in the analysis. The first and the second run are driven in the free condition and the third run in the load condition, with the cognitive secondary task. Visual anticipation is seen in deviations of gaze from straight ahead $(0$ degrees) towards the occlusion point. In the beginning of the straight segment $(x=0)$ the occlusion point is located at eccentricity of $12^{\circ}$, increasing in eccentricity while the driver approaches the curve.

Fig. 4 shows the mean percentage of anticipation in both curves, separately for the two task-conditions and the three consecutive runs. A $2 \times 2$ repeated measures ANOVA (curve $\mathrm{x}$ task condition, the two no-load runs averaged) showed a significant task condition effect on visual anticipation $(F(1,8)=7.497 ; p=0.026)$. The curves differed significantly $(F(1,8)=8.919$; $p=0.017)$, while paired t-tests showed a significant task effect in both curves separately 
(right: $t(8)=2.361, p=0.046$; left: $t(8)=3.299, p=0.011$ ). Visual anticipation reduced on average 13.4 percentage units (SD 17.1, Cohen's $d=1.062$ ) in the right hand curve and 8.5 percentage units (SD 7.7, Cohen's $d=1.244)$ in the left hand curve. The results of the right hand curve suggest a decreasing trend with successive runs, as hypothesized. However, regression analysis with a linear trend assumption did not yield a significant result.
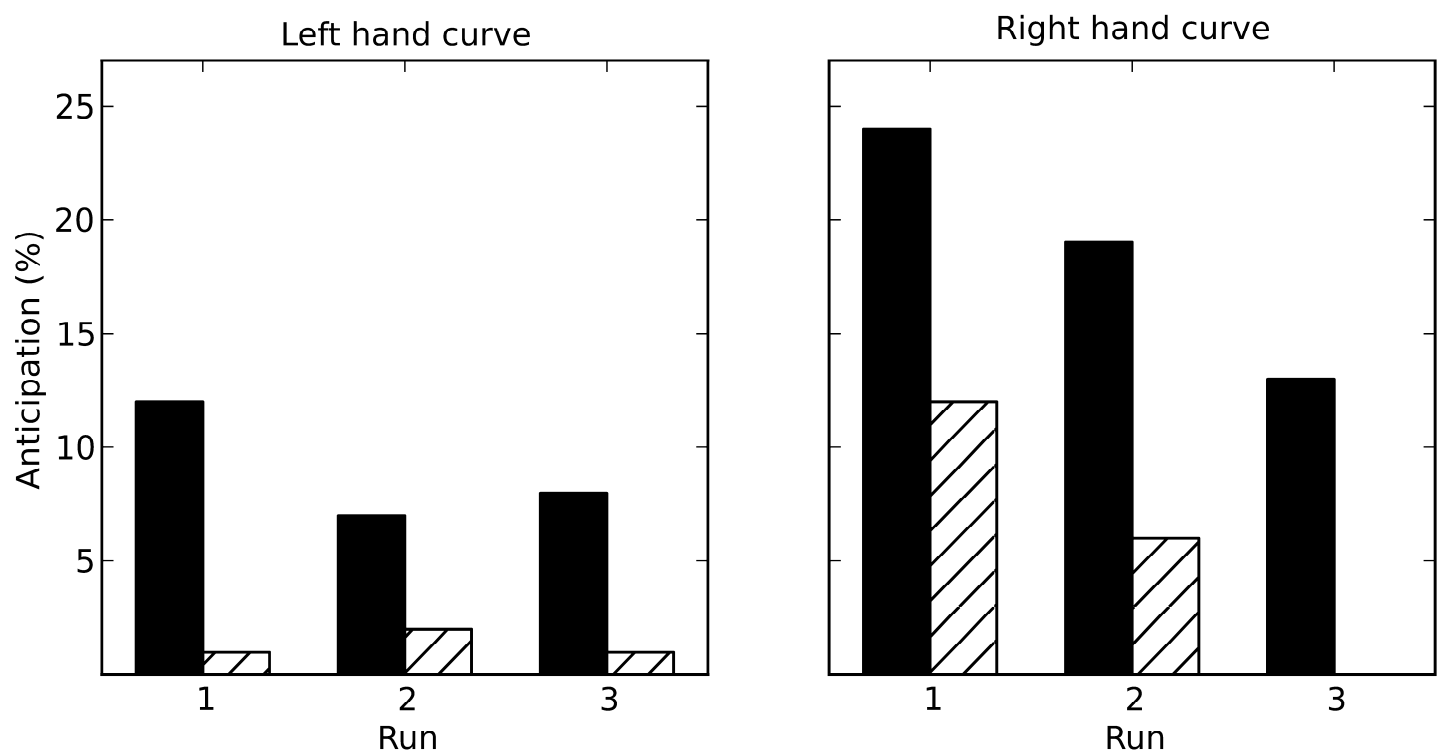

Free $\square]$ Loaded

Fig. 4. Visual anticipation over the runs in different task conditions. Percentage of time spent on looking towards the occlusion point (y-axis) over runs 1-3 (x-axis) in the left hand curve (left) and the right hand curve (right). Solid bars represent the mean value of anticipation in the free condition and hatched bars represent the mean value of anticipation in the load condition.

\subsection{Gaze concentration}

Ninety percent contour level was calculated over the straight segment representing concentration of gaze distribution over time (for illustration see e.g. Land \& Lee, (1994)). Contour size decreased in both curves under the secondary task (right hand curve: from 61.3 (SD 25.3) to 48.4 (SD 30.0) squared degrees, Cohen's d=0.465; left hand curve: from 53.7 (SD 20.4 ) to 43.0 (SD 24.1) squared degrees, Cohen's $d=0.479$ ). However, the effect of task 
condition on contour size in a $2 \times 2$ repeated measures ANOVA (curve $x$ task condition, the two no-load conditions averaged, with natural logarithm normalization) was only marginally significant $(F(1,8)=5.165, p=0.053)$.

\subsection{Driving speed and secondary task effect on speed}

If anticipation is indeed reduced due to increased cognitive load, drivers might, in the interest of safety, be expected to compensate for the increased risk by reducing their speed. Drivers have previously been shown to lower their speed in order to compensate for demands intrinsic to the road environment (Harms, 1991). However, the effect of cognitive load on speed may not be that straightforward because the drivers might not have driven at their preferred speed in the absence of cognitive load due to adherence to speed limits (although our procedure of occluding the instrument cluster might reduce this effect). According to Couyoumdjian, Di Nocera \& Ferlazzo (2002) and Recarte \& Nunes (2002) there is an optimal level of speed for a driver and a road which minimizes mental resources needed, such that deviation in either direction requires additional resources. Consequently, if the optimal level of speed for the road is higher than the speed chosen because of speed restrictions, then the speed would be expected to increase with cognitive load, because there are less resources available for speed regulation.

We calculated three speed measures for the road segments. A subject's straight segment speed was defined as the highest speed attained on the straight segment before turning into the curve. Cornering speed was defined as the minimum value to which the vehicle's speed fell during the curve driving manoeuvre. Both measures were computed for individual runs for all subjects separately for the curves. (Although the straight segment connecting the curves was the same in both cases, the sight of the upcoming curve might conceivably have an effect on driving speed on the straight). Thirdly, speed reduction from the straight to the curve was computed for each run (Table 1 ). 
Table 1. Speed measures before and in the curves, and their difference. Straight line speed is the average of maximum speeds on the straight section and the cornering speeds the average of the minimum speeds in the curve. The two curves and the task conditions were calculated separately. Standard deviations are in parenthesis.

\begin{tabular}{lccc}
\hline & $\begin{array}{c}\text { Straight } \\
(\mathrm{km} / \mathrm{h})\end{array}$ & $\begin{array}{c}\text { Cornering } \\
(\mathrm{km} / \mathrm{h})\end{array}$ & $\begin{array}{c}\text { Speed drop } \\
(\mathrm{km} / \mathrm{h})\end{array}$ \\
\hline Right, free & $59.4(8.3)$ & $46.5(6.4)$ & $12.9(3.9)$ \\
Right, loaded & $56.7(7.7)$ & $46.0(5.8)$ & $10.7(3.4)$ \\
Left, free & $55.8(8.1)$ & $40.4(5.8)$ & $15.3(4.0)$ \\
Left, loaded & $54.9(6.8)$ & $40.8(4.5)$ & $14.1(3.1)$ \\
\hline
\end{tabular}

Task condition had a weak effect on the straight segment speed approaching the right hand curve (Cohen's $d=0.337, t(8)=1.886, p=0.096$ ) but practically no effect before the left curve (Cohen's $d=0.120, t(1,8)=0.733, p=0.484)$. Cornering speed showed no task condition effect at all. However, a $2 \times 2$ repeated measures ANOVA (curve $x$ task condition) showed a significant effect of the task condition $(F(1,8)=6.714, p=0.032)$ : drivers eased their speed off more in the free condition than in the load condition (Cohen's d right: 0.601 , left: 0.335 ).

\subsection{The secondary task performance}

The mean rate of answers and percentage of mistakes and passes in the SPASAT performance were calculated for each driver. The drivers had mean answer interval of $3.1 \mathrm{~s}$ (SD 0.46). On average, $8.9 \%$ (SD 4.8) of answers were wrong and $3.0 \%$ (SD 2.0) were passed, resulting on average $11.9 \%$ (SD 6.0) incorrect responses.

The secondary task increased self-reported physical load $(t(1,9)=2.452, p=0.037$, Cohen's $d=1.148)$, mental load $(t(1,9)=5.566, p<0.001$, Cohen's $d=2.328)$ and concentration on vehicle controls $(t(1,9)=2.924, p=0.017$, Cohen's $d=0.764)$. Drivers also reported more negative valence under the secondary task $(t(1,9)=2.590, p<0.029$, Cohen's $d=0.957)$. 


\section{DISCUSSION}

We demonstrated in an on-road study that drivers switch their visual attention between the road (far point or tangent point) and the occlusion point when driving along a straight road segment approaching an open curve. Glancing toward the occlusion point appears to be part of normal driving, and is done by drivers spontaneously. The glances toward the occlusion point are most plausibly interpreted as visual anticipation of potential oncoming vehicles, obstacles and road alignment.

A working memory task was shown to reduce looking towards the occlusion point and lead to marginally $(p=0.053)$ more concentrated gaze within the straight segment. Cognitive load only had a minor effect on the speeds used on the straights and no effect within curves. This suggests that visual anticipation is a less automatized or more controlled process than for example speed regulation (for automatic and controlled processes, see Shiffrin \& Schneider, 1977). Specifically, cognitive load did not lead to speeding, which could have explained the marginally significant concentration of gaze (Rogers, Kadar \& Costall, 2005) and could have been a possible explanation for reduced visual anticipation as well. The speed regulation result could have been different if the speedometer had not been occluded (Recarte \& Nunes, 2002).

We observed no consistent decrease in looking towards the occlusion point over successive runs, contrary to the initial hypothesis. This could suggest that either more runs are needed for the driver to learn the road, or that visual anticipation is mainly exercised for spotting oncoming vehicles and obstacles, and to a lesser extent for road alignment. However, as we only observed ten drivers in two curves, this negative result can be considered tentative at most.

Anticipatory visual behaviour on the straight preceding the curve provides a possible explanation for the findings by Underwood et al. (1999) that in open curves drivers fixate more in the area near the tangent point than in closed curves. As drivers do anticipate before open curves, they might thereafter feel confident to focus on steering in the curves (fixating the tangent point) because they know that the curve will be free of oncoming vehicles for a couple of seconds. 
Land \& Lee (1994) suggested that drivers seek out the tangent point 1-2 s before they enter a curve and keep their gaze fixed on the tangent point until unwinding. In future studies, it would be important to study whether visual anticipation continues to some extent within curves as suggested by Underwood et al. (1999). However, it is a challenge for on-road research to collect data which reliably distinguishes between the tangent point and the occlusion point because in many curves the two points lie very close to each other.

More looking towards the occlusion point was observed in the right hand curve than in the left hand curve. The difference might be related to physical differences in the curves. The left hand curve had a smaller radius and greater inclination than the right hand curve. In the left hand curve the occlusion point was located at an angle of 25 degrees left in the beginning of the straight road section, compared to 12 degrees in the right hand curve. Inspection of video recordings suggests that in the left hand curve the occlusion point had such a high eccentricity that drivers were not able to fixate it without a head turn which might explain the smaller amount of looking time. Interestingly, they did not look increasingly at the area between the occlusion and far points, suggesting that they trusted more on their peripheral vision.

If we parallel visual anticipation in the current setting with visual search performed by drivers in order to spot hazards, the cognitive mechanism underlying the present results can be outlined. SPASAT needs maintaining of the last digit in working memory and manipulation of working memory content, namely mental arithmetic and updating last digit in working memory. Working memory tasks which need both maintenance and manipulation of working memory contents (see D'Esposito, Postle, Ballard \& Lease, 1999) interfere with visual search (Han \& Kim, 2004; Anderson, Mannan, Rees, Sumner \& Kennard, 2010), especially if the targets are not highly salient (Anderson, Mannan, Rees, Sumner \& Kennard, 2008). The effect can be attributed to executive processing capabilities which are needed in both tasks (Han \& Kim, 2004; Anderson et al., 2010; de Fockert, Rees, Frith \& Lavie, 2001).

From this perspective, we suggest that the cognitive mechanism could be modelled with following axioms:

1. Executive working memory is essential for SPASAT and for performing visual anticipation. 
2. Verbal executive working memory task and visual search cannot be executed simultaneously, in other words, executive working memory is a bottleneck (Pashler, 1994).

3. The two tasks compete for use of executive working memory.

4. In time-constrained environments dual-tasking will reduce execution of each task, not just delay it.

The fourth assumption is important for understanding reduction of anticipation. It is of no use to anticipate after some point, so if the task is delayed for too long it will be aborted. Still, the present data suggest that drivers might be prioritizing the secondary task over anticipation because sometimes there was no visual anticipation at all (even though the drivers were instructed to prioritize safety over the secondary task).

\section{Conclusions}

Drivers were observed to anticipate open curves by switching their visual attention between the road and the occlusion point. A demanding working memory task was shown to reduce this visual anticipation. The result is consistent with previous studies, which have shown reduction in glances to mirrors and speedometer, and visual scanning at street crossings. We suggest that the behaviour could be understood in terms of competition for executive working memory resources, where the secondary task is at least as prioritized as visual anticipation. This research clarifies the interplay of working memory and visual control of driving in an ecologically valid setting, and may be used as a basis for developing cognitive models of the role of working memory processes in car driving. 


\section{References}

Anderson, E. J., Mannan, S. K., Rees, G., Sumner, P., \& Kennard, C. (2008). A role for spatial and nonspatial working memory processes in visual search. Experimental Psychology, 55(5), 301-312. doi: 10.1027/1618-3169.55.5.301

Anderson, E. J., Mannan, S. K., Rees, G., Sumner, P., \& Kennard, C. (2010). Overlapping functional anatomy for working memory and visual search. Experimental Brain Research. 200(1), 91-107. doi: 10.1007/s00221-009-2000-5

Charlton, S. G. (2007). The role of attention in horizontal curves: a comparison of advance warning, delineation, and road marking treatments. Accident Analysis \& Prevention, 39(5), 873-885. doi: 10.1016/j.aap.2006.12.007

Cohen, A. S., \& Studach, H. (1977). Eye movements while driving cars around curves. Perceptual and Motor Skills, 44(3 Pt 1), 683-689.

Couyoumdjian, A., Di Nocera, F. \& Ferlazzo, F. (2002) Spontaneous speed: theoretical and applied considerations. In D. de Waard, K.A. Brookhuis, J. Moraal, and A. Toffetti (Eds.), Human Factors in Transportation, Communication, Health, and the Workplace (pp. 175188). Maastricht, the Netherlands: Shaker.

D’Esposito, M., Postle, B. R., Ballard, D., \& Lease, J. (1999). Maintenance versus manipulation of information held in working memory: an event-related fMRI study. Brain and Cognition, 41(1), 66-86. doi: 10.1006/brcg.1999.1096

Donges, E. (1978). A two-level model of driver steering behavior. Human Factors, 20(6), 691707.

Fildes, B. N., \& Triggs, J. (1985). The effect of changes in curve geometry on magnitude estimates of road-like perspective curvature. Stimulus, 37(3), 218-224.

Fockert, J. W. de, Rees, G., Frith, C. D., \& Lavie, N. (2001). The role of working memory in visual selective attention. Science, 291(5509), 1803-6. doi: 10.1126/science.1056496

Gibson, J. J. (1958). Visually controlled locomotion and visual orientation in animals. Ecological Psychology, 10(3-4), 161-176. 
Gronwall, D. M. (1977). Paced auditory serial-addition task: a measure of recovery from concussion. Perceptual and Motor Skills, 44(2), 367-373.

Gruzdaitis, L., Karola, J., Kotiranta, H., Lamble, D. \& Summala, H. (2004). Mental load and visual search at street crossings. 3rd International Conference on Traffic \& Transport Psychology, Nottingham, UK, 5-9 September 2004.

Han, S., \& Kim, M. (2004). Visual search does not remain efficient when executive working memory is working. Psychological Science, 15(9), 623-8. doi: 10.1111/j.09567976.2004.00730.x

Harbluk, J., Noy, Y., Trbovich, P., \& Eizenman, M. (2007). An on-road assessment of cognitive distraction: Impacts on drivers' visual behavior and braking performance. Accident Analysis \& Prevention, 39(2), 372-379. doi: 10.1016/j.aap.2006.08.013

Harms, L. (1991). Variation in drivers' cognitive load. Effects of driving through village areas and rural junctions. Ergonomics, 34(2), 151-160.

Kandil, F. I., Rotter, A., \& Lappe, M. (2009). Driving is smoother and more stable when using the tangent point. Journal of Vision, 9(1), 1-11. doi: 10.1167/9.1.11

Kandil, F. I., Rotter, A., \& Lappe, M. (2010). Car drivers attend to different gaze targets when negotiating closed vs. open bends. Journal of Vision, 10(4), 1-11. doi: 10.1167/10.4.24

Kauranen, T., Lamble, D., Laakso, M. \& Summala, H. (1997). Matkapuhelimen ja viestin käsittely ajon aikana: liikenteen kaksi uutta turvallisuusongelmaa (Managing with cell phone and message during driving: two new traffic safety problems) (Traffic Research Unit Reports No. 32). Helsinki: University of Helsinki.

Land, M. F, \& Lee, D. N. (1994). Where we look when we steer. Nature, 369(6483), 742-744. doi: $10.1038 / 369742 \mathrm{a} 0$

Land, M. F., \& Horwood, J. (1995). Which parts of the road guide steering? Nature, 377(6547), 339-40. doi: 10.1038/377339a0

Lamble, D., Kauranen, T., Laakso, M. \& Summala, H. (1999). Cognitive load and detection thresholds in car following situations: safety implications for using mobile (cellular) telephones while driving. Accident Analysis \& Prevention, 31(6), 617-623. 
Lehtonen, E., Dahlström, I., Hiltunen, H., \& Summala, H. (2010). Automaattivaihteisen auton edut ikäkuljettajilla: kokeellinen tutkimus (Advantages of automatic transmission for elderly drivers.) (Trafi publications 4/2010). Helsinki: TraFi.

Mourant, R. R., \& Rockwell, T. H. (1972). Strategies of visual search by novice and experimental drivers. Human Factors, 14(4), 325-35.

Pashler, H. (1994). Dual-task interference in simple tasks: data and theory. Psychological Bulletin, 116(2), 220-244.

Recarte, M. A., \& Nunes, L. M. (2000). Effects of verbal and spatial-imagery tasks on eye fixations while driving. Journal of Experimental Psychology: Applied, 6(1), 31-43. doi:10.1037//0278-7393.6.1.31

Recarte, M., \& Nunes, L. (2002). Mental load and loss of control over speed in real driving. Towards a theory of attentional speed control. Transportation Research Part F: Traffic Psychology and Behaviour, 5(2), 111-122. doi: 10.1016/S1369-8478(02)00010-4

Reimer, B. (2009). Impact of cognitive task complexity on drivers' visual tunneling. Transportation Research Record, 2138, 13-19. doi: 10.3141/2138-03

Rogers, S., Kadar, E., \& Costall, A. (2005). Gaze patterns in the visual control of straight-road driving and braking as a function of speed and expertise. Ecological Psychology, 17(1), 19-38. doi: $10.1207 / \mathrm{s} 15326969 e c 01701 \_2$

Salvucci, D. D., \& Gray, R. (2004). A two-point visual control model of steering. Perception, 33(10), 1233-1248. doi: 10.1068/p5343

Sampson, H. (1956). Pacing and performance in a serial addition task. Canadian Journal of Psychology, 10, 219-225. doi: 10.1037/h0083679

Shiffrin, R. M., \& Schneider, W. (1977). Controlled and automatic human information processing: II. Perceptual learning, automatic attending and a general theory. Psychological Review, 84(2), 127-190.

Shinar, D., McDowell, E. D. \& Rockwell, T. H. (1977). Eye movements in curve negotiation. Human Factors, 8(4), 237-238. 
Summala, H., Nieminen, T., \& Punto, M. (1996). Maintaining lane position with peripheral vision during in-vehicle tasks. Human Factors, 38(3), 442-451. doi:

$10.1518 / 001872096778701944$

Underwood, G., Chapman, P. Crundall, D. Cooper, S. \& Wallén, R. (1999). The visual control of steering and driving: Where do we look when negotiating curves? In Gale, AG (Ed.) Vision in vehicles VII. Amsterdam: Elsevier, pp. 245-252.

Wann, J. P., \& Swapp, D. K. (2000). Why you should look where you are going. Nature Neuroscience, 3(7), 647-648. doi:10.1038/76602

Victor, T., Harbluk, J., \& Engström, J. (2005). Sensitivity of eye-movement measures to invehicle task difficulty. Transportation Research Part F: Traffic Psychology and Behaviour, 8(2), 167-190. doi: 10.1016/j.trf.2005.04.014 


\section{Acknowledgements}

We are grateful to Harri Hiltunen who acted as driving instructor, to students Riina Lipponen, Outi Myllymäki, Mirjami Peltokorpi, Minna Pyysalo and Malla Saarinen for assistance in data collection and to Isa Dahlström who made the initial analysis of subjective workload. Harri Hiltunen, Henri Kotkanen, Markus Mattsson and Jami Pekkanen gave helpful feedback on the manuscript. 